\title{
조석과 계절풍을 고려한 EST에 의한 동해연안의 극치해면 산정 Estimation of Extreme Sea Levels with Consideration of Tide and Monsoon by Using EST at the East Coast
}

\author{
강주환* · 김양선* - 박선중** • 심재설*** \\ Ju Whan Kang*, Yang Seon Kim*, Seon Jung Park** and Jae-Seol Shim***
}

\begin{abstract}
요 지 : 극치해면 추정을 위해 EST기법을 동해연안에 적용하였다. 과거 60 년간 발생한 TY급 태풍 51 개에 의한 해 일고를 $\mathrm{ADCIRC}$ 모형으로 계산하여 트레이닝세트에 포함하였고, 태풍을 제외한 매년 발생하는 최대해일고를 계절풍 에 의한 것으로 간주하여 계절풍에 따른 해일고도 응답벡터로 설정하였다. 조위조건을 입력벡터에 포함시켜 태풍시 에는 고·저조 조건을 포함시켰으며 계절풍시에는 대·소조 조건을 입력벡터에 반영하였다. 이때 두 경우 모두 연 주조를 감안하여 응답벡터를 작성하였다. 적용결과를 기존연구와 비교한 결과 정 등(2008)의 결과와 거의 일치하고 있어 본 방법의 적합성을 입증할 수 있었다.
\end{abstract}

핵심용어 : EST기법, 극치해면, ADCIRC, 계절풍, 조석, 동해연안

\begin{abstract}
EST has been applied to the East Coast to estimate extreme sea levels. Surge heights induced by 51 typhoons which have occurred last 60 years were calculated by ADCIRC model. The training set which is consist of surge heights by both typhoon and monsoon was constructed. The maximum surge height of the year excluding the one by typhoon is considered to be the surge height by monsoon. High/low tide conditions and spring/neap tide conditions were considered for constructing input vectors of typhoon and monsoon, respectively. The annual tide is also considered in response vectors for each case. The result is in accord with Jeong et al. (2008), which implies validity of the present study.
\end{abstract}

Keywords : EST, extreme tidal level, ADCIRC, monsoon, tidal condition, the East Coast

\section{1. 서 론}

극치해면 추정은 해안방재의 주요 관심사로서 과거에는 설 계폭풍을 설정하여 해석하는 방법과 과거사상을 확률분포함 수법과 같은 모수적 방법으로 해석하는 방법 등이 주로 사용 되었다. 그러나 한 개의 사상이 태풍특성변화를 모두 감당할 수 없다는 결정적 단점이 있는 설계폭풍법은 현재 거의 사용 되지 않고 있으며, 자료수가 많지 않은 경우 소수의 극치자 료에 매우 민감할 수밖에 없는 모수적 방법의 사용빈도도 점 차 줄고 있는 추세이다(Toro, 2010). 근래에는 컴퓨터 발달에 힘입어 EST(empirical simulation technique)기법과 같이 과 거사상을 비모수적 방법으로 해석하는 방법과 매개변수 결정 에 결합확률을 도입하는 JPM(joint probability method)방법 등이 널리 사용되고 있다. 이들은 태풍을 무수히 발생시켜 모 의된 해일자료로부터 빈도해석을 시행하는 방법으로서 태풍 및 해일의 과거자료가 흔치 않고 공간적 분포에 대한 정보 역
시 불충분한 경우에 특히 장점이 있다.

$\mathrm{EST}$ 기법은 적용 해역에서 관측된 자료에 대한 의존도가 큰 반면 JPM방법은 기존에 발생했던 사상에 국한하지 않고 가 능한 모든 경우에 대한 모의가 이루어지므로 더 우수한 방법 으로 평가되지만 수천번의 태풍-해일 모의가 필요하므로 막 대한 계산시간이 소요된다는 단점이 있다. 반면 EST기법은 특정 사상이 선정되면 미리 산정된 응답벡터로부터 결과가 얻 어지므로 JPM방법과는 달리 매 사상별로 수치모의가 필요한 것이 아니기에 효율성에서 큰 장점이 있다(Divoky and Resio, 2007). 이 방법에 대한 적용사례는 최근 크게 늘고 있어 Shrestha et al.(2011), Goring et al.(2011), Resio and Irish (2008) 등을 비롯해 적지 않은 국외 연구사례가 있으며, 국 내에서도 서 등(2009)이 국내 연안의 빈도별 해일고 산정을 위해 EST기법을 적용한 바 있다.

우리나라 서해안과 같이 조석의 영향이 지배적인 해역에서 는 해일고의 변동폭보다 조위의 변동폭이 훨씬 더 크기 때문

\footnotetext{
* 목포대학교 토목공학과 (Corresponding author : Ju Whan Kang, Dept. of Civil Engineering, Mokpo National University, Muan-gun, Jeonnam 534-729, Korea. jwkang@mokpo.ac.kr)

** (주)혜인이엔씨 기술연구소 (Technology R\&D Institute, Hyein E\&C)

*** 한국해양연구원 기후변화연안재해연구부 (Korea Ocean R\&D Institute)
} 
Table 1. Tide data period and amplitudes of main tidal constituents

\begin{tabular}{ccccc}
\hline \hline \multirow{2}{*}{ Station } & \multirow{2}{*}{ Period } & \multicolumn{3}{c}{ Amplitude $(\mathrm{cm})$} \\
\cline { 3 - 5 } & & $\mathrm{Sa}$ & $\mathrm{M}_{2}$ & $\mathrm{~S}_{2}$ \\
\hline Ulsan & $1963 \sim$ & 11.0 & 15.9 & 7.6 \\
Pohang & $1972 \sim$ & 11.5 & 3.2 & 0.7 \\
Mukho & $1966 \sim$ & 10.8 & 6.4 & 2.2 \\
Sokcho & $1963 \sim$ & 11.9 & 7.0 & 2.5 \\
\hline
\end{tabular}

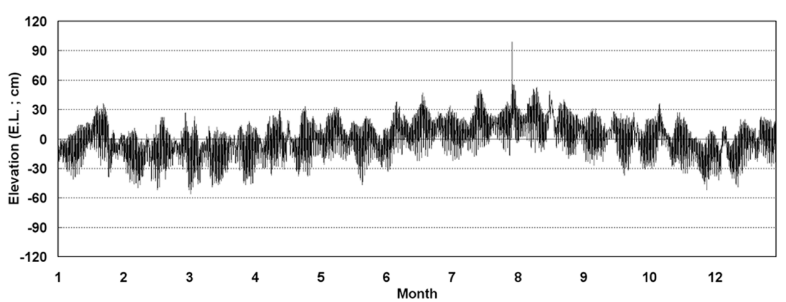

(a) Observed

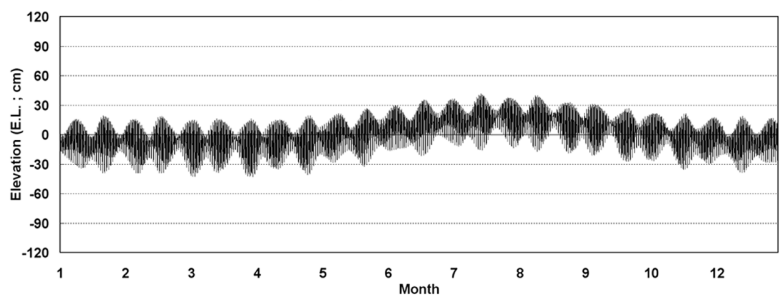

(b) Predicted

Fig. 1. Time series of tidal elevation.

에 이러한 해역에서 $\mathrm{EST}$ 기법을 적용할 경우에는 조위조건 반 영시 세심한 주의를 요하게 된다. 이 경우 적용할 수 있는 EST기법을 Goring et al.(2011)이 제안하여 적용한 바 있다. 기존의 일반적인 EST기법은 국내 남해안 및 동해안과 같이 조석의 영향이 그리 크지 않은 해역에 적용할 수 있으며 이 경우에도 조석조건 처리에 주의해야 한다. 본 연구에서는 조 석의 영향이 크지 않은 동해안에서 일반적인 EST기법 적용 성에 대하여 고찰하였다. 이때 조석이 감안된 상태에서 태풍 뿐 아니라 계절풍에 따른 빈도별 고극조위를 산정함으로써 재 현주기가 작은 경우의 해면고 산정도 가능하도록 하였다. 국 립해양조사원에서 운영하고 있는 동해안의 울산이북의 6 개 검 조소 중 연안에서 벗어난 울릉도와 자료기간이 10 년 미만이 어서 모수적 방법을 적용한 타연구와의 비교가 어려운 후포 를 제외한 4 개 검조소를 적용대상으로 선정하였으며 관측기 간 및 주요 분조의 진폭을 Table 1에 제시하였다.

\section{2. 해면고의 성분별 특성}

\section{1 조위 및 해일고 특성}

울산검조소에서 2004년 1년간 관측된 조위 시계열 및 관측 조위로부터 추출된 조화상수에 의한 계산치 시계열을 Fig. 1에 제시하였다. 이들의 차를 조위편차 또는 해일고라 하며 Fig. 2 에 보인 바와 같이 태풍 또는 계절풍에 의해 발생된다. 2004 년의 경우 울산해역에 영향을 미친 태풍은 5 번(0407, 0410,

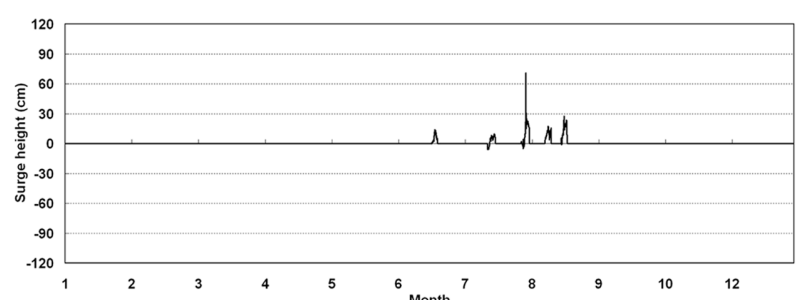

(a) By typhoon

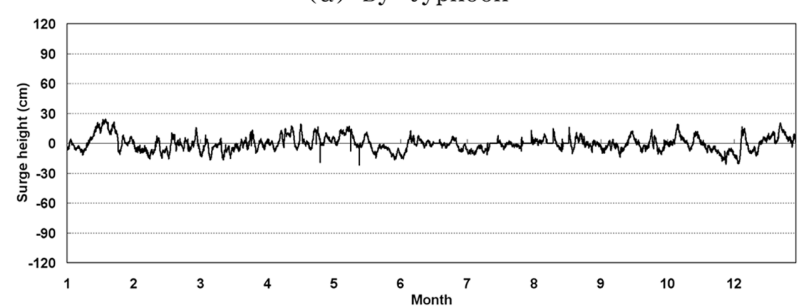

(b) By monsoon

Fig. 2. Time series of surge height.

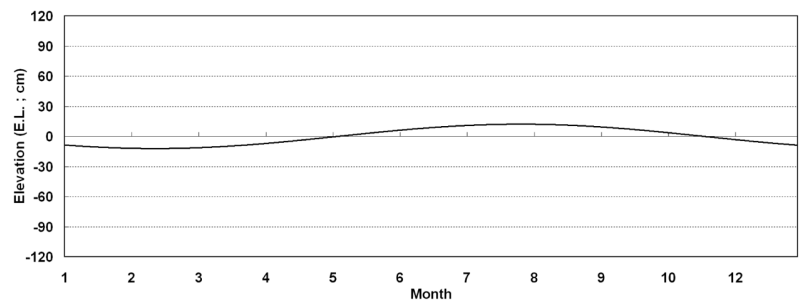

(a) $\mathrm{Sa}$

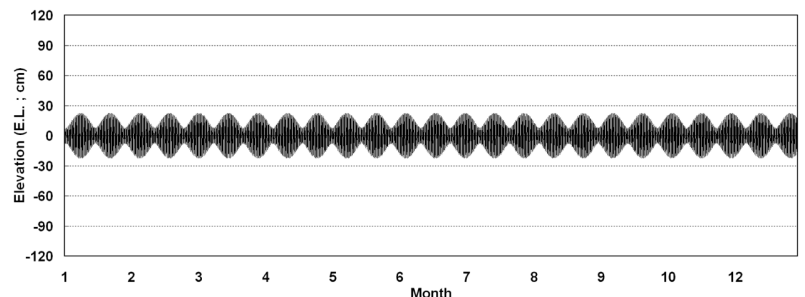

(b) $\mathrm{M} 2+\mathrm{S} 2$

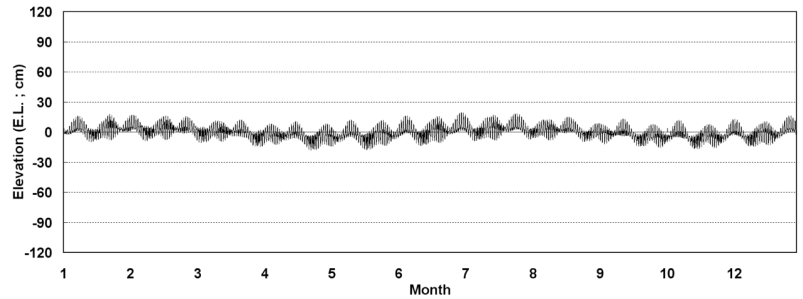

(c) Others

Fig. 3. Division of predicted tidal level into tidal constituents.

$0415,0416,0418)$ 발생하였으며, 태풍영향기간 동안 발생한 조위편차는 전적으로 태풍에 의한 것이라는 가정하에 조위편 차를 태풍과 계절풍으로 분리하였다. Fig. 1의 조위예측치의 경우 Fig. 3에 제시된 $\mathrm{Sa}$ 분조의 영향으로 하절기 조위면이 매 우 높게 형성되고 있으며, $\mathrm{M}_{2}$ 분조와 $\mathrm{S}_{2}$ 분조에 의해 대·소 조 변화를 보이게 된다. 울산검조소에서 기왕최고극조위는 Fig. 4에 자세히 보인 바와 같이 2004년 7월 19일 발생한 $133 \mathrm{~cm}$ 이다. 이상의 그림에 나타나 있듯이 이 때 발생한 태 풍 $\mathrm{MEGI}(0415)$ 에 의한 기왕최고극조위는 $\mathrm{Sa}$ 분조의 연최고 점과 대조기 고조시에 맞물려 발생한 것이다. (편의상 Fig. 1 


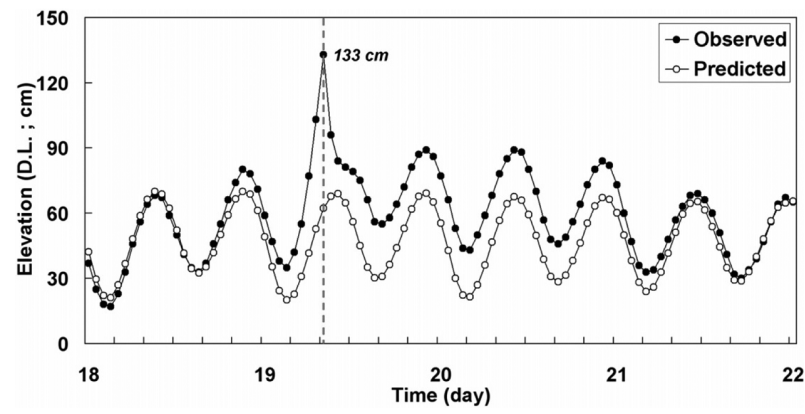

Fig. 4. Tidal elevation at the period of typhoon MEGI(0415).

Fig. 3은 평균해수면 기준, Fig. 4는 D.L. 기준으로 각각 작성되었음.) $\mathrm{EST}$ 기법을 적용하여 극치해면을 산정하고자 할 경우 이러한 조석관련 해역별 특성이 충분히 숙고되어야 할 것이며, 특히 고·저조 및 대·소조 뿐 아니라 연주조 등 조 위변화에 대한 이해와 태풍 및 계절풍 발생에 따른 해일고 산 정 등이 적절하게 감안되어야 한다.

\section{2 계절풍 고려 필요성}

조차가 큰 서해안의 경우 극치해면은 주로 연중 대조기에 태풍 및 계절풍 모두에 의해 야기될 수 있는 반면 동해안의 경우에는 하절기 태풍에 의해 발생하는 것이 일반적이다 (강 등, 2011). 이는 Fig. 1과 Fig. 2에서도 확인할 수 있는 사항으로 동해안에서는 연주조 성분이 최대가 되어 평균해수 면이 연중 최고치에 이르는 하절기에 태풍시기도 일치하므로 이 때 주로 연최고극조위 또는 극치해면이 발생하게 된다. 따 라서 재현주기가 큰 경우의 극치해면은 하절기 태풍시기에 집 중됨을 볼 수 있지만, 태풍 영향이 미미한 해인 경우 연최고 극조위가 계절풍에 의해 발생할 수도 있게 된다. 물론 이 경 우의 해면고는 그리 높지 않게 되므로 작은 재현주기의 극치 해면이 발생하게 된다. 따라서 재현주기가 큰 경우 뿐 아니 라 작은 경우의 해면고도 산정할 경우 태풍의 영향 뿐 아니 라 계절풍에 대한 해석이 함께 요구되며 이와 함께 조석에 대 한 고려가 수반되어야 한다.

\section{EST 기법}

\subsection{EST기법의 일반적 특성}

EST 기법(Scheffner et al., 1999)은 폭풍사상과 같이 확률 적이고 다중 매개변수적인 특징을 갖는 시스템의 전 과정을 모의하기 위한 통계학적 모형이다. 즉, 과거 사상을 분석하여 일련의 발생표본을 구축한 후 미래에도 과거와 통계적으로 유 사한 발생환경이 유지될 것이라는 가정하에 표본으로부터 임 의의 사상을 추출하게 된다. 이때 추출된 사상은 태풍의 규 모를 묘사하는 입력벡터와 그에 따른 해일고를 나타내는 응 답벡터로 구성되는데, 추출후 복원되어 다음 추출에도 표본 에 포함시키게 된다. 또한, 과거 발생 사상의 한계를 극복
하기 위해 추출된 표본은 다음에 설명되는 'Random walk interpolation' 기법이 적용된다.

$\mathrm{EST}$ 기법은 단지 과거 사상을 뽑아내는 것에 그치는 것이 아니라 선택된 사상의 입력벡터로부터 Nearest neighbor random walk를 수행하여 과거 사상과 다른 사상을 발생시키 게 된다. 이와 같이 하여 새로운 사상에 대한 입력벡터가 정 해지면 이에 대한 응답벡터를 트레이닝세트에 있는 과거 사 상의 응답벡터 공간상에서 보간법에 의하여 구하게 된다.

$V_{j}$ 라는 벡터가 선정되었고 그 주변에 $K$ 개의 최근접 벡터 $(k=1, K)$ (중요도에 따라 가중치를 두어 거리를 계산해서 결 정된 벡터)가 존재할 때 새로운 사상은 다음과 같이 결정된다.

$$
W=V_{j}+\sum_{k=1}^{K} 2\left(N_{k}-0.5\right) \cdot\left(U_{k}-V_{k}\right)
$$

여기서 $N_{k}$ 는 $0 \sim 1$ 사이의 난수이므로 $2\left(N_{k}-0.5\right)$ 는 -1 에서 1 사이의 난수가 된다.

EST기법에 대한 자세한 소개는 Sheffner et al.(1996), Shrestha et al.(2011), 서 등(2009)에 제시되어 있다.

\subsection{ADCIRC모형}

태풍에 의한 해일 발생에 대한 트레이닝세트를 구성하기 위 해 태풍에 대한 정보 뿐 아니라 각 태풍이 영향을 미친 주 변 해석대상지점에서의 해일고 역시 산정되어야 한다. 이를 산정하기 위한 폭풍해일모형으로 SLOSH, ADCIRC, CH3D, POM, FVCOM 등이 있는데(Sheng et al., 2010), 특히 최근 비구조격자 유한요소 유동모형인 $\mathrm{ADCIRC}$ 모형이 가장 빈 번한 적용사례를 보이고 있다(Mattocks and Forbes, 2008; Heerden et al., 2007; Shrestha et al., 2011). 본 연구에서도 태풍에 의한 해일모의 관련내용은 2차원 ADCIRC 모형을 적 용한 국립해양조사원(2012) 결과를 사용하였다. 이 연구에서 해상풍 산정은 Holland(1980) 모형을 이용하였으며 태풍 정 보는 RSMC(Regional Specialized Meteorological Center) Tokyo-Typhoon Center에서 제공하는 Best Track Data를 사 용하였고, 이 자료는 6시간 간격으로 태풍의 이동경로, 최대 풍속, 중심기압 등을 포함한다. 1951년부터 2010년까지 발생 한 총 1573 개의 태풍 가운데 우리나라에 영향을 미친 TY (typhoon)급 51개와 STS(severe tropical storm)급 91개 태풍 을 선별한 후 $\mathrm{ADCIRC}$ 모형을 이용해 동해안 각 지점에서 태 풍영향기간 중 최대해일고를 계산하였다. 이때 각 지점에 영 향을 미친 태풍의 선정기준은 해당 지점이 태풍 중심으로부 터 $500 \mathrm{~km}$ 반경 내에 위치할 경우와 최저중심기압이 1000 $\mathrm{hPa}$ 이하인 경우로 제한하였다. 이렇게 선정된 TY급 및 STS 급 태풍의 제원을 비롯한 자세한 내용은 국립해양조사원 (2012)에 제시되어 있다.

\section{3 입력벡터와 응답벡터}

$\mathrm{EST}$ 기법은 특정한 장소에 영향을 준 과거 사건들의 분석 
으로부터 시작된다. 태풍이나 계절풍 등으로 규정되는 사건 들 중 선택된 데이터베이스를 이용하여 사건의 영향과 특성 을 매개화한다. 태풍을 정의하는 매개변수들이 입력벡터를 구 성하고 태풍의 영향을 응답벡터로 나타낸다. 입력벡터와 응 답벡터들은 태풍과 관련된 영향의 생애주기 모의를 위한 기 초로 사용되며 트레이닝세트라 부른다. 각 지점의 입력벡터 로는 태풍의 경우 각 지점에서 최대해일고가 발생한 시점에 서의 1) 지점과 태풍의 눈 사이의 거리 $(\mathrm{km}), 2)$ 지점에서의 풍속 $(\mathrm{m} / \mathrm{s}), 3)$ 지점에서의 해면기압 하강량 $(\mathrm{hPa}), 4)$ 태풍 눈 의 진행속도 $(\mathrm{km} / \mathrm{h}), 5)$ 조위조건(중조기 고·저조) 등을 사용 하였다. 계절풍의 경우 입력벡터는 1) 매년 비태풍 시기의 최 대해일고, 2) 조위조건(대·소조기 고조) 등이며, 두 경우 모 두 응답벡터는 해일 발생시 연주조에 의한 평균해면고가 반 영된 (D.L. 상의) 조위면으로 구성된다. 이와 같이 새로운 사 상에 대한 입력벡터가 정해지면 이에 대한 응답벡터를 트레 이닝세트에 있는 과거 사상의 응답벡터 공간상에서 보간법에 의하여 구하게 된다.

\section{4. 적용 및 결과해석}

\section{1 태풍 트레이닝세트 구성}

서 등(2009)의 연구에서는 TY급 태풍과 함께 STS급 태풍 도 트레이닝세트에 포함시켜 56년 동안 발생한 201개 태풍 을 대상으로 해석한 바 있다. STS급 태풍까지 포함시킬 경 우 정확도는 개선되겠지만 효율성은 다소 둔화될 수 있다. $\mathrm{EST}$ 기법의 장점 중 한 가지로 가상태풍을 모의하여 그 결과 를 트레이닝세트에 포함시켜 해석할 수 있다는 점을 들 수 있다. 즉, 유용한 태풍자료가 많지 않은 상태에서 공간적 분 포마저 편중되어 있을 경우 그 지역에서 실제 발생하지는 않 았지만 발생할 가능성이 충분한 가상태풍 또는 경로를 가상 적으로 평행이동시킨 태풍 등을 상정하여 실제 태풍과 함께 트레이닝세트에 포함시켜 해석하기도 한다(Divoky and Resio, 2007). 이 경우 전체 태풍이 많을수록 가상태풍이 선택될 가 능성이 감소하게 된다. 즉, 트레이닝세트가 지나치게 많은 태 풍으로 구성되어 있을 경우 가상태풍을 포함시키는 효과가 감 소하게 되며 효율성도 떨어지게 된다. 따라서 트레이닝세트 를 구성할 때 $\mathrm{TY}$ 급, $\mathrm{STS}$ 급, $\mathrm{TS}$ 급, $\mathrm{TD}$ 급 중 어느 정도까지 의 태풍을 포함시킬 것인가는 정확도와 효율성을 감안하여 판 단해야 할 것이다.

이러한 STS급 태풍의 포함 영향성을 파악하기 위하여 간 단한 해석을 실시하였다. 해석대상지역은 울산으로서 울산에 영향을 미친 TY급 태풍 40개에 STS급 태풍 66개가 포함된 경우(TY+STS)와 포함되지 않은 경우(TY)의 해석결과를 Fig. 5 에 제시하였다. 강도가 약한 많은 수의 태풍이 포함 된 관계로 $\mathrm{STS}$ 급 태풍이 포함된 결과가 재현주기가 작은 경 우에서는 다소 크게 나타나고 있지만, 트레이닝세트에 포함 된 일정 규모 이상의 강도가 큰 태풍은 TY급에 치중되어 있

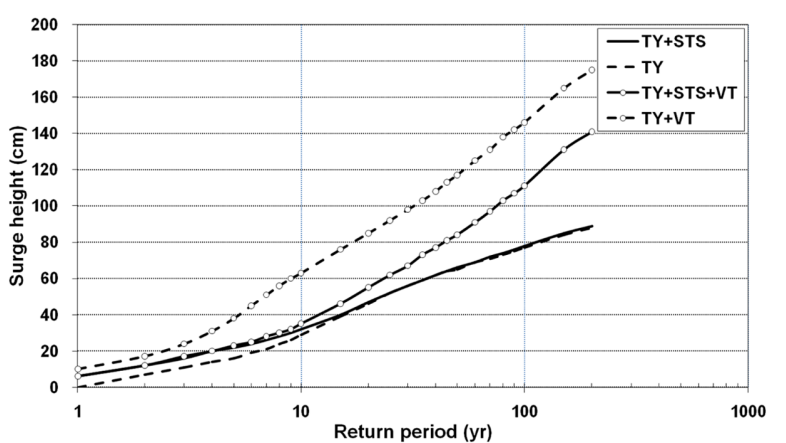

Fig. 5. Effect on the surge height by including STS with/without virtual typhoon (VT).

으므로 해석결과 역시 재현주기 20년 이상에서는 거의 동일 한 결과를 보이고 있다. 또한 해일고가 $100 \mathrm{~cm}$ 인 임의의 가 상태풍(virtual typhoon; VT)을 설정하여 트레이닝세트에 추 가하여 분석한 결과 STS급까지 포함된 경우(TY+STS+VT) 가상태풍의 영향이 재현주기 30 년 이상에 집중되고 있다. 그 러나 TY급만 포함시킨 경우 $(\mathrm{TY}+\mathrm{VT})$ 가상태풍의 영향은 재 현주기가 작은 경우를 포함하여 모든 빈도에서 훨씬 크게 나 타나고 있다. 이와 같이 태풍에 대한 트레이닝세트에 TY급 태풍만 포함시킨 결과가 STS급 태풍까지 포함시킨 결과에 비 해 재현주기가 큰 경우에서 결과의 차이가 없을 뿐 아니라 가상태풍 포함시 훨씬 유연한 결과를 기대할 수 있게 된다. 또한 극치해면의 재현주기가 작은 상황이란 심한 태풍 없이 도 발생할 수 있는 상황을 의미하므로 Fig. 1에서 보듯이 조 위가 높은 상황이 우선적으로 전제되어야 하며, 이 상황에서 자주 발생하고 있는 계절풍에 의해 초래되는 경우가 더 일 반적이라 할 수 있다. 따라서 재현주기가 작은 경우에 있어 서도 STS급 태풍을 포함시키는 것보다 조석과 계절풍을 고 려하는 것이 더욱 실제적이라고 할 수 있으므로, 계절풍 해 석이 수반된 본 연구에서는 태풍과 관련된 트레이닝세트 구 성시 STS급 태풍은 배제하고 TY급 태풍만 포함시켜 해석하 였다.

\section{2 조석 및 계절풍 고려 효과}

$\mathrm{EST}$ 기법에서 조석을 고려하는 방법은 태풍시와 계절풍시 로 구분되어 적용된다(Scheffner et al., 1999). 태풍시에는 태 풍제원이 기술된 입력벡터의 추가된 한 요소로 조위조건이 부 여되는데, 창조 $(0)$, 고조 $(+1)$, 낙조 $(0)$, 저조 $(-1)$ 등 각 조시가 입력벡터로 설정된다. 이때 고조위 조건은 $\mathrm{M}_{2}$ 분조 진폭을 반 영함으로써 중조기 고조조건을 부여하였으며, 여기에 태풍 영 향시기의 D.L. 상의 평균해수면값을 가산함으로써 연주조 성 분까지 반영된 응답벡터가 설정되는 방법을 고안하여 적용하 였다.

계절풍의 경우 태풍과 달리 지속시간이 조석주기를 초과하 므로 고 - 저조 조건 대신 대·소조 조건을 부여하였다. 즉, 태풍을 제외한 상태에서 계절풍에 의한 연최고조위편차 발생 시기를 특정한 후에 조시와 관련된 입력벡터를 작성하였다. 중 


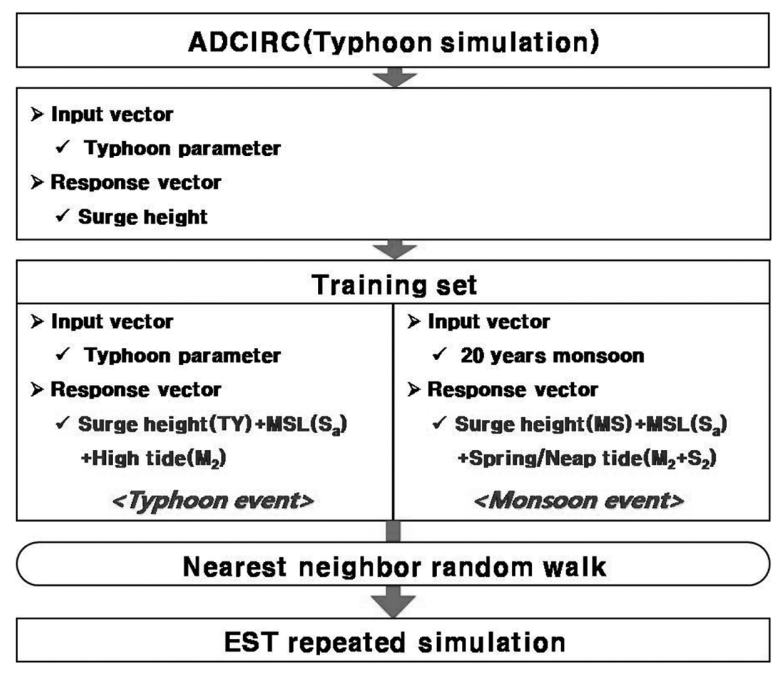

Fig. 6. Schematic diagram of EST application procedure.

조 $(0)$, 대조 $(+1)$, 중조 $(0)$, 소조 $(-1)$ 등을 설정하여 중조기엔 $\mathrm{M}_{2}$ 분조의 진폭만 감안하는 반면 대조기와 소조기에는 $\mathrm{M}_{2}$ 분 조의 진폭에 $\mathrm{S}_{2}$ 분조의 진폭을 가감하여 조위조건을 부여한 후 이를 해일고에 가산함으로써 응답벡터를 설정한다. 이때 자료 기간 동안 매년 발생하는 조위예측치의 연최대값 중 가장 작 은 값을 산정하여 응답벡터의 최소값으로 설정한다. 이렇게 함 으로써 하절기 조위가 높아지는 연주조 성분도 반영하게 될 뿐 아니라 계절풍에 의한 해면고의 최소값이 설정되어 재현주 기가 작은 경우의 해석결과에 정확도를 높일 수 있게 된다. 이러한 일련의 과정을 Fig. 6 에 정리하여 도시하였으며, 울산 검조소에서의 적용결과를 Fig. 7에 예시하여 나타내었다.

고·저조, 대·소조, 연주조 등의 감안이 빈도별 해면고에 미치는 영향성을 파악하기 위하여 태풍 및 계절풍 각각에 있 어서 조석고려 여부에 대한 결과를 Fig. 7(a)와 (b)에 제시하 였다. 연주조 성분을 고려하는 경우 태풍시 결과에 미치는 영 향은 매우 크게 나타나고 있으며 이는 Fig. 3(a)에서와 같이 태풍시기와 연주조의 최대시기가 거의 일치함에 연유하는 것 으로 추정된다. 비태풍시 역시 연주조의 영향성이 작지 않은 것으로 나타나고 있지만 재현주기가 작은 경우에는 계절풍 발 생시기가 연주조가 최저가 되는 동절기이기에 연주조 감안효 과가 나타나지 않고 있다. 또한 태풍시 연주조에 추가하여 고. 저조를 고려한 영향은 재현주기가 큰 경우 다소 크게 나타나 고 있는 반면 계절풍시에는 대·소조 영향이 모든 재현주기 에서 매우 크게 나타나고 있다. 고·저조와 연주조가 감안된 태풍의 결과 및 대·소조와 연주조가 감안된 계절풍의 결과 를 두 경우의 결합확률과 함께 Fig. 7(c)에 제시하였다. 재현 주기 50 년 이상의 경우에는 계절풍 고려가 결합확률에 미치 는 영향이 미미한 반면 재현주기 10 년 이하에서는 계절풍 고 려의 영향성이 매우 큰 것으로 나타나고 있다. 이와 같이 동 해안 해역에서의 극치해면 산정시 조석 및 계절풍에 대한 이 해가 매우 중요하며, EST 적용시 이를 적절하게 반영하여야 할 것이다.

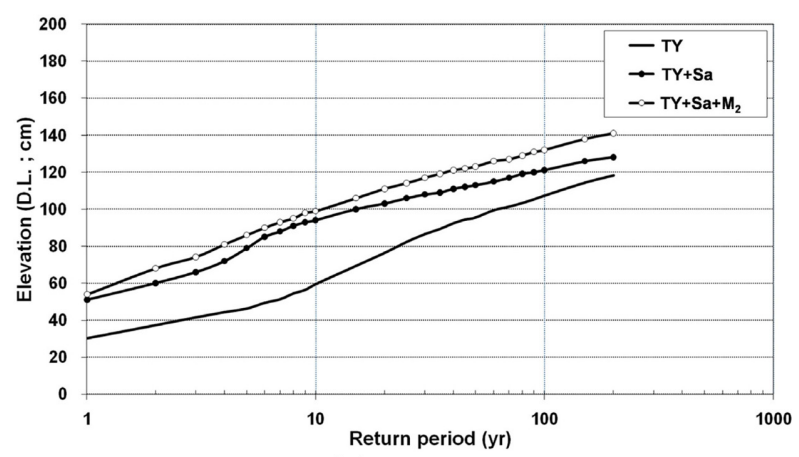

(a) Typhoon

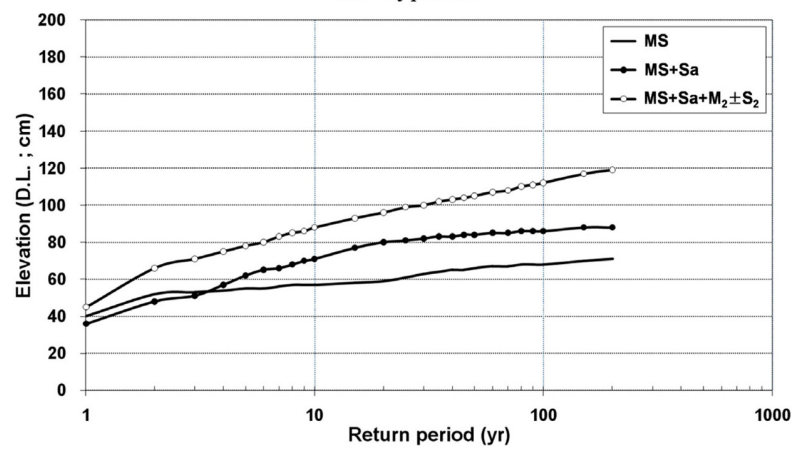

(b) Monsoon

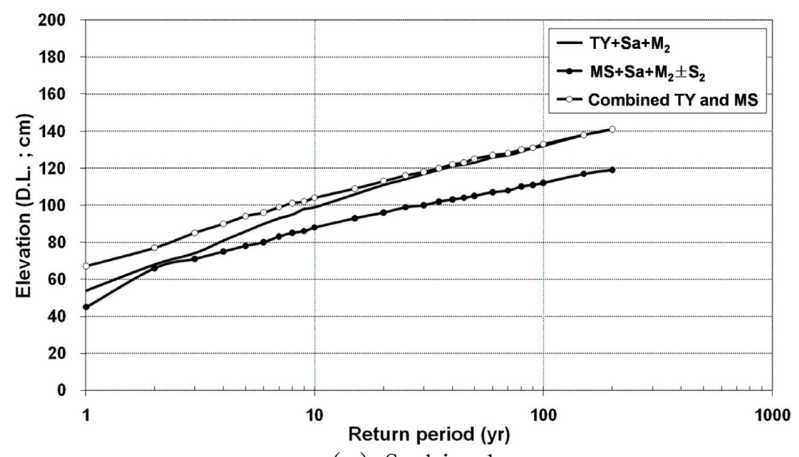

(c) Combined

Fig. 7. Frequency curves with/without typhoon and monsoon.

\section{3 적용 결과}

최종적으로 조석과 계절풍이 감안된 동해연안 지점에서 결 합확률을 산정하기 위하여 각 경우에 대하여 200년 기간을 500 회 모의하였다. 그 결과를 Table 2에 제시하였으며, 정 등 (2008) 및 서 등(2009)의 결과와 함께 Fig. 8에 비교하였다. 동해안 4개 지점에 대하여 비교한 결과 연최고조위에 대한 모 수적 방법을 사용한 빈도분석결과인 정 등(2008)의 결과가 본 연구결과와 매우 유사한 결과를 보이고 있는 반면 서 등 (2009)의 결과는 다소 큰 차이를 보이고 있다. 관측조위 자 료를 기반으로 한 정 등(2008)의 결과는 조석과 계절풍이 모 두 내포되어 있는 반면 서 등(2009)의 경우 Fig. 7(a)에서 태 풍시 고·저조 조건만 반영했을 뿐 계절풍과 대·소조 및 연 주조에 대한 고려가 전혀 없음을 감안하면 당연한 결과라 할 수 있다. 따라서 EST기법을 통해 해일고만 산정할 경우는 별 문제가 없지만 극치해면고를 산정할 경우에는 고조를 감안한 태풍에 대한 해석 뿐 아니라 연주조와 대·소조 및 계절풍 등을 함께 고려하여야 할 것이다. 


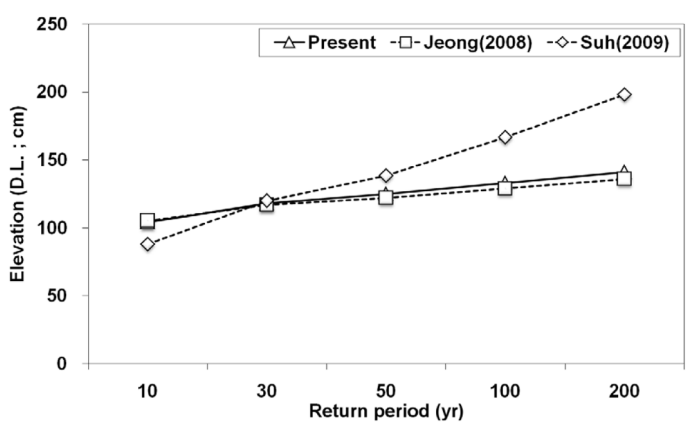

(a) Ulsan

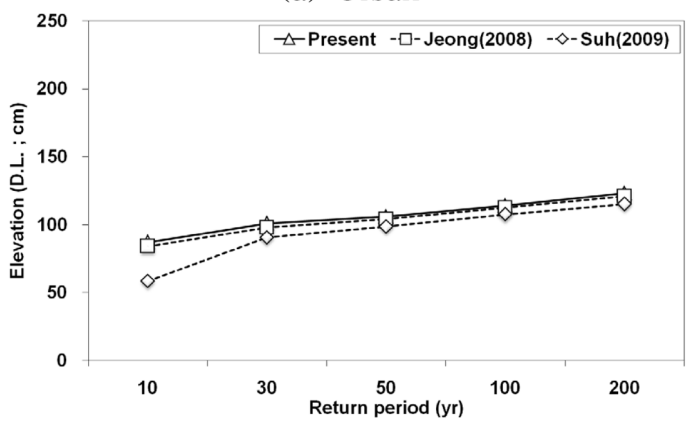

(b) Pohang

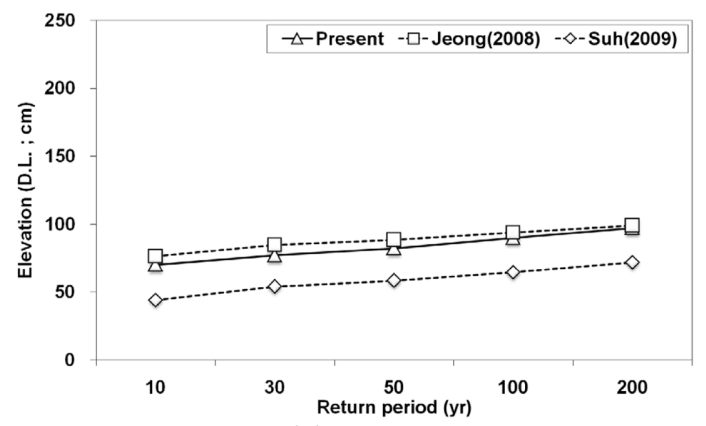

(c) Mukho

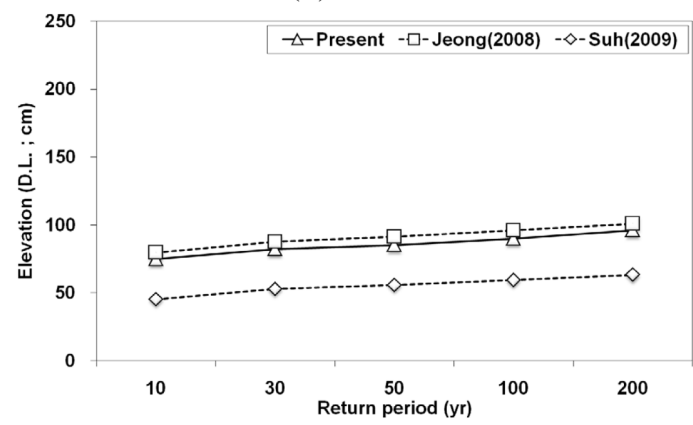

(d) Sokcho

Fig. 8. Comparison of frequency result with other studies.

Table 2. Frequency result obtained from combined effect of typhoon and monsoon $(\mathrm{cm})$

\begin{tabular}{ccccccc}
\hline \hline \multirow{4}{*}{ Ulsan } & & \multicolumn{5}{c}{ Return period } \\
\cline { 3 - 7 } & Typhoon & 99 & 117 & 123 & 132 & 141 \\
& Monsoon & 88 & 101 & 105 & 112 & 120 \\
& Combined & 104 & 118 & 125 & 133 & 141 \\
& Typhoon & 69 & 78 & 82 & 88 & 95 \\
\multirow{4}{*}{ Pohang } & Monsoon & 85 & 100 & 106 & 114 & 123 \\
& Combined & 87 & 101 & 106 & 114 & 123 \\
& Typhoon & 70 & 77 & 82 & 90 & 97 \\
\multirow{4}{*}{ Mukho } & Monsoon & 62 & 65 & 66 & 68 & 69 \\
& Combined & 70 & 77 & 82 & 90 & 97 \\
& Typhoon & 69 & 80 & 84 & 90 & 96 \\
& Monsoon & 72 & 76 & 78 & 81 & 84 \\
& Combined & 75 & 82 & 85 & 90 & 96 \\
\hline
\end{tabular}

\section{5. 결 론}

동해안의 4 개 검조소에서 조위조건과 계절풍이 감안된 극 치해면을 산정하기 위해 $\mathrm{EST}$ 기법을 적용한 결과 다음과 같 은 결론을 얻을 수 있었다.

(1) 태풍자료가 많아질수록 가상태풍의 효과가 줄어들며 재 현주기가 작은 경우에서는 계절풍을 고려하는 것이 효과적이 기 때문에 태풍 트레이닝세트를 구성하기 위해 STS급 태풍 까지 고려할 필요는 적은 것으로 나타났다.

(2) 태풍과 계절풍 모두 입력벡터와 응답벡터 작성시 조석상
황을 적절하게 반영시켜야 한다. 태풍의 경우 중조기 고조, 계절풍의 경우 대·소조에 대한 정보 입력이 필요하며 두 경 우 모두 연주조 성분에 따른 평균해면 정보가 반영되어야 한다.

(3) 계절풍에 대한 해석 없이도 재현주기가 큰 경우 극치 해면 산정에는 큰 무리가 없지만 재현주기가 작은 경우 적절 한 계절풍 해석이 요구된다.

(4) 조석에 대한 처리가 불완전한 상태에서 EST가 적용된 서 등(2009)의 결과와 본 연구결과는 다소 차이를 보이고 있 지만 조석과 계절풍 등의 고려가 내포되어 있는 모수적 방법 인 정 등(2008)의 결과와는 매우 높은 일치를 보이고 있어 본 방법이 유효함을 입증할 수 있었다.

\section{감사의 글}

본 연구는 지식경제부 지식경제 기술혁신사업의 연구비 지 원(20103020070080)에 의해 수행되었습니다. 또한 본 연구 는 한국해양연구원 주요사업 '태풍해일 침수범람 예측 및 재 해도 작성기술 개발' 사업의 지원으로 일부 수행되었습니다.

\section{참고문헌}

강주환, 김양선, 조홍연, 심재설 (2011). 국내 연안의 해일강도

특성. 한국해안 · 해양공학회논문집, 23(6), 458-465.

국립해양조사원 (2012). 해안침수예상도 제작 및 보급(목포외 17 개소).

서경덕, 양영철, 전기천, 이동영 (2009). 경험모의기법을 이용한 
한반도 주변 해역에서의 극치해면 분석. 한국해안·해양공학 회논문집, 21(3), 254-265.

정신택, 김정대, 고동휘, 윤길림 (2008). 한국 연안 최극 고조위 의 매개변수 추정 및 분석. 한국해안해양공학회논문집, 20(5), 482-490.

Divoky, D. and Resio, D.T. (2007). Performance of the JPM and EST methods in storm surge studies. 10th International Workshop on Wave Hindcasting and Forecasting, and Coastal Hazard Symposium, North Shore, Oahu, Hawaii.

Goring, D.G., Stephens, S.A., Bell, R.G. and Pearson, C.P. (2011). Estimation of extreme sea levels in a tide-dominated environment using short data records. Journal of Waterway, Port, Coastal, and Ocean Engineering, 137(3), 150-159.

Holland, G.J. (1980). An analytic model of the wind and pressure profiles in hurricanes. Monthly Weather Review, 108, 1212-1218.

Mattocks, C. and Forbes, C. (2008). A real-time, event-triggered storm surge forecasting system for the state of North Carolina. Ocean Modelling, 25, 95-119.

Resio, D.T. and Irish, J. (2008). Hurricane characteristics along the Northern US Gulf of Mexico coast for surge prediction. Solutions to Coastal Disasters Congress 2008, 170-184.

Scheffner, N.W., Borgman, L.E. and Mark, D.J. (1996). Empirical simulation technique based storm surge frequency analyses. Journal of Waterway, Port, Coastal, and Ocean Engineering,
122(2), 93-101.

Scheffner, N.W., Clausner, J.E., Militello, A., Borgman, L.E., Edge, B.L. and Grace, P.J. (1999). Use and application of the empirical simulation technique; User's guide. US Army Corps of Engineers.

Sheng, Y.P., Zhang, Y. and Paramygin, V.A. (2010). Simulation of storm surge, wave, and coastal inundation in the Northeastern Gulf of Mexico region during Hurricane Ivan in 2004. Ocean Modelling, 35, 314-331.

Shrestha, P.L., Lenaburg, R.T., Scheffner, N.W., Rezakhani, M., Hamilton, D. and Cydzik, K. (2011). Storm surge study of the Hawaiian islands using the EST method. World Environmental and Water Resources Congress 2011, 2286-2294.

Toro, G.R., Resio, D.T., Divoky, D., Niedoroda, A.W. and Reed, C. (2010). Efficient joint-probability methods for hurricane surge frequency analysis. Ocean Engineering, 37, 125-134.

van Heerden,I.L., Kemp, G.P. and Mashriqui, H. (2007). Use of the ADCIRC storm surge model for hurricane Katrina surge predictions and levee forensic studies. GSP 161 Embankments, Dams, and Slopes, ASCE, 1-9.

원고접수일: 2012년 4월 30일

수정본채택: 2012년 6월 12일

게재확정일: 2012년 6월 12일 